University of Windsor

Scholarship at UWindsor

OSSA Conference Archive

OSSA 2

May 15th, 9:00 AM - May 17th, 5:00 PM

\title{
The Limits of the Dialogue Model of Argument
}

J Anthony Blair

University of Windsor

Follow this and additional works at: https://scholar.uwindsor.ca/ossaarchive

Part of the Philosophy Commons

Blair, J Anthony, "The Limits of the Dialogue Model of Argument" (1997). OSSA Conference Archive. 10. https://scholar.uwindsor.ca/ossaarchive/OSSA2/papersandcommentaries/10

This Paper is brought to you for free and open access by the Conferences and Conference Proceedings at Scholarship at UWindsor. It has been accepted for inclusion in OSSA Conference Archive by an authorized conference organizer of Scholarship at UWindsor. For more information, please contact scholarship@uwindsor.ca. 


\title{
THE LIMITS OF THE DIALOGUE MODEL OF ARGUMENT
}

\author{
J. Anthony Blair \\ Department of Philosophy \\ University of Winds or \\ (C) 1998, J. Anthony Blair
}

\section{Abstract:}

The paper starts from scepticism that all argumentation is dialogical or that all dialogue types are argumentation. The hypothesis is that the concepts of dialectic and dialogue are not isomorphic, at least as applied to argumentation. The paper will cover: (a) a review of the conceptions of dialectic and of dialogue in the argumentation literature, (b) an analysis of these concepts, (c) a critical assessment of the limits of the discussion of dialogue as a model for argumentation (d) a discussion of alternative models of argumentation, (e) an exploration of the implications of the proposed models for the relation between argument and rhetoric.

$* * *$

\section{Introduction}

In a set of recent books, Douglas Walton has developed the idea that arguments and argumentation can be illuminated by the model of the dialogue. 1 Some arguments actually occur in the form of dialogues. Walton thinks that the thoroughly articulated model of the two-party dialogue discussion aimed at resolving a disagreement that was developed by van Eemeren and Grootendorst (1984) is helpful for some types of argument, but that it does not fit all. He argues that we need as well models of other kinds of dialogue in order to understand other kinds of argument, or perhaps all of argument. Against this background, in this paper I look closely at dialogues to see how they can model arguments and try to show that the dialogue model has its limitations.

Readers may be familiar with Walton's typology of dialogues. Walton and Krabbe $(1995,66)$ give a recent version (not intended to be exhaustive), which distinguishes dialogue types primarily according to their purposes: the goals of the dialogue and of its participants. They distinguish the following: persuasion or critical discussion dialogues, negotiation dialogues, inquiry dialogues, deliberation dialogues, information-seeking dialogues, eristic dialogues, and various mixtures of these. Although Walton and Krabbe do not explicitly say that these are all types of argument-dialogues (my term for dialogues in which arguments play an essential role), their interest seems to be clearly in the relationship between argument and dialogue. That is the relationship that interests me in the present paper.

Given the many senses of the term 'argument' distinguished nowadays, it is necessary to specify the sense in use here. The following characterization by Walton captures it:

An argument is, from a pragmatic point of view, a tool that has various uses. The primary use of argument is to steer commitment towards a specific proposition, called the 'conclusion' of the argument. . . . The pragmatic use of argument takes the semantic structure of an argument and deploys it, most often by putting individual links of argument together in an argumentation sequence directed towards a final conclusion, that is, by linking chains of premises and conclusions. 
The user of the argument . . . attempts to steer the commitment of . . . the one to whom the argument is directed ... towards the conclusion aimed at by the argument. Accordingly, there are two sides to every argument . . . . (Walton 1990, 38)

The objectives of the present paper call for a different kind of classification of argument-dialogues than Walton and Krabbe's. Rather than the purpose of the dialogue, I am interested in the ways in which the arguments figure in the dialogue exchange. The basis of the following classification is the complexity of the argument ingredient at each turn of a dialogue, because, as it will become clear, at a certain stage in the increasing complexity of the argument turns, there is a qualitative change in the nature of the dialogue. The classification begins with the simplest, and proceeds to the most complex.

\section{Dialogues Types}

The following account arranges argument-dialogues into four groups of increasing complexity within the groups and from each group to the next.

\section{GROUP A.}

In one class of argument dialogues, the rules permit just one party to control the direction of the exchange by way of leading it. Typically, the objective is for the controlling party to force the other into a contradiction with some initial proposition, or between propositions, offered in support of some initial proposition. At each turn after the opening one, each party responds to the immediately preceding turn in the exchange.

1. Question and Answer dialogues with yes/no questions. One side (usually the opponent) asks yes/no questions. The other party, the proponent, answers Yes or No. The opponent's questions must ask for a yes/no answer either to a simple proposition, or to compound propositions the components of which are simple propositions previously affirmed by the proponent or implied by propositions previously affirmed by the proponent. This type of dialogue is modelled in Figure 1:

Figure 1.

\begin{tabular}{|l||l||l||}
\hline $\begin{array}{l}\text { Turn } \\
\text { No. }\end{array}$ & Q (opponent) & \multicolumn{1}{||}{ A (proponent) } \\
\hline \hline 01 & & $\mathrm{P}$ \\
\hline \hline 02 & $\mathrm{r} ?$ & yes \\
\hline \hline 03 & $\mathrm{r} \supset \mathrm{s} ?$ & yes \\
\hline \hline 04 & $\mathrm{t} ?$ & yes \\
\hline \hline 05 & $(\mathrm{t} \& \mathrm{~s}) \supset-\mathrm{p} ?$ & yes \\
\hline \hline 06 & $\mathrm{p} \& \sim \mathrm{p} !$ & oh dear \\
\hline \hline
\end{tabular}


2. Open-ended Question and Answer dialogues. The opponent asks open-ended questions which require simple propositions as answers.

3. A combination of yes/no and open-ended Question and Answer dialogues. Many dialogues of Plato have this form. Here is an exchange from The Republic that illustrates it.

Socrates: ... Simonides thought this to be just, to give to each man what is proper to him, and he called this what is due?

Polemarchus: Surely

S: ... if someone asked him: "What does the craft we call medicine give that is due, and to whom?" what would his answer be?

$\mathrm{P}:$ It is the craft which prescribes medicines and food and drink for our bodies.

S: And what does the craft which we call cooking give that is due and fitting and to whom?

P: It adds flavour to food.

S: What, and to whom, does that craft give which we would call justice?

P: It must follow from what was said before, Socrates, that it is that which benefits one's friends and harms one's enemies.

S: Now, when people are not ill ... the physician is no use to them?

P: Yes.

S: Nor is the pilot when they are not sailing?

P: Yes.

S: So to people who are not fighting a war the just man is useless?

P:No.

S: Justice then is useful also in peace time?

P:Yes. $\underline{2}$

Notice that no argument is provided at any given turn of the dialogues in this first group. Instead, the turns establish the ingredients of the arguments - the premises and conclusions. Each argument as such is kept in the interlocutors' heads as they proceed.

Most of Plato's dialogues, and the sort of argument game Aristotle seemed to have in mind in the Topics, are Group A dialogue types.

\section{GROUP B.}

In a somewhat more complicated class of interactions, the rules will permit fuller exchanges.

4. Single simple arguments. One side might be permitted in one turn to produce a simple argument in answer to the questions of the other side. (If we think of an argument in Walton's sense 
as an invitation to infer the acceptability of a proposition from cited reasons, a "simple argument," as I use the term, is one which invites just one inference). The questioner could raise questions about either the reasons or the inference link of such arguments.

5. Multiple simple arguments. A somewhat more complicated exchange would be one in which the answerer was permitted to offer more than one simple argument for the proposition questioned in a given turn.

6. Combination of 4 and 5, with challenges supported by simple arguments. A further complexity would occur if the questioner were permitted to offer simple arguments to support his doubts about the reasons or the inference links of the answerer's argument.

7. Combination of 4-6, with roles symmetrical. If the roles of questioner and answerer could be switched back and forth between the parties during the argument, the dialogue would become yet more complex.

What all the dialogues of group B have in common is that only simple arguments are permitted at each turn. An implication of this requirement is that in such dialogues the speaker would be permitted to offer reasons in support of the premises or of the inference links in his arguments only if these were challenged by the interlocutor. If such supporting reasons were offered along with the initial argument, there would be at least two invited inferences, and thus the argument would no longer be simple.

An example of argument-dialogues of Group B would seem to be the dialogue-games of P. Lorenzen (1982) and Kuno Lorenz (1982). It looks to me as though the Permissive Persuasive Dialogue model defined by Walton and Krabbe (1995) may belong here too, but I am not sure they want to restrict each interlocutor at each move to simple arguments.

Dialogues of the first two sorts, groups A and B, also share the feature that what is supplied by each participant at each turn is a direct response to what was stated or asked in the previous turn. Thus these might be termed "fully-engaged" dialogues. $\underline{3}$

It should perhaps be made clear that although argument is the essential ingredient of such exchanges, that does not preclude ancillary kinds of move at any given turn, such as requests for and the provision of definitions, distinctions, explanations, examples, and so on.

\section{GROUP C.}

A third degree of complexity is introduced when the dialogue rules allow in a given turn anything beyond a yes/no answer, a single simple or compound proposition, or a simple argument. Once support for a premise or an inference link of an argument is permitted in addition to the argument at a given turn of the dialogue, there is the beginning of a sea-change in the character of the interaction. Consider some sub-types, again in order of increasing complexity.

8. Premise or inference-link support. Perhaps the simplest of this group is the dialogue in which one or both parties are permitted to provide in a single turn a line of argument for a proposition. By a "line of argument" I mean a simple argument, along with one or more additional simple arguments 
supporting its premises or inference link. (Others might prefer the term "chain" of arguments.) Any such premise-support or link-support argument is in effect an answer to a question about the acceptability of that premise or link. This is one kind of indirect support for the main conclusion. We will see others below.

9. Support for the support. There is no reason in principle why support for the premises or inference links of these supporting arguments should not also be included, at the discretion of the interlocutor whose turn it is. However, each additional iteration adds to the complexity of the turn.

10. Multiple lines of argument. Complexity increases in a different direction once more than one line of argument is permitted in any turn.

11. Multiple lines of argument plus support for the support. A combination of 9. and 10. could in principle result in a very long and complicated turn indeed.

In fact, although type 11. is not the most complicated kind of turn imaginable, as we will see in a moment, nevertheless it illustrates how dialogues of group $\mathrm{C}$ are significantly different from those of types $\mathrm{A}$ and $\mathrm{B}$. Once an interlocutor in a dialogue is permitted to offer and defend several lines of argument for a proposition, he is no longer responding to a single question or challenge from the other party.

So far all the argument-dialogue types described have the feature that nothing other than arguments which have as their conclusion a proposition in question is envisaged at a given turn in the dialogue, whether that proposition is the main point at issue, a premise of a supporting argument or an inference link of a supporting argument.

\section{GROUP D.}

The next level of complexity is to permit at any one turn, in addition to the above, two other kinds of indirect arguments in support of the main proposition at issue.

12. Additional indirect supporting arguments. These are: (a) arguments intended as refutations of alternatives to the main proposition, and (b) arguments intended as refutations of arguments which are aimed at refuting the main proposition.

13. All of the above, 1.-12., combined. Once we combine 11. and 12. in the argument types permitted at any given turn, we have reached the most complicated possible argument turn. Here we have the possibility of a whole case $\underline{4}$ for a position presented in a single turn.

It is difficult to place examples of argument-exchange dialogues as those envisaged by Barth (1982b), or those which would fit van Eemeeren and Grootendorst's model (1984), along the above continuum. Barth clearly has in mind exchanges in which the audience responds to the speaker as an active partner in the discussion, the verbal reactions of the audience are considered in detail, and there is interplay between the locutions of the occupants of the "dialectical roles" (see Barth, 1982a, viii). Since she contrasts such "dialectical" argumentation with the rhetorical argumentation analysed by Perelman and Olbrechts-Tyteca (1958), in which the speaker appeals to the concessions of the audience but the audience does not interact with the speaker, the kind of argumentdialogue Barth is thinking of would seem to belong somewhere in Group C. Van Eemeren and Grootendorst (1984) seem to me to leave open the possibility that a turn in the dialogue can reach level 13 complexity, yet they 
also seem to have in mind exchanges in which the two sides interact during the course of the argumentation, which cannot happen of someone is making a level 13 case for his position. So it is not clear to me whether their model can be mapped on the above continuum.

\section{Implications of complexity}

What I want to suggest is that dialogues approaching level 13 complexity are different in kind from those of groups A and B This point can perhaps be appreciated by considering some examples.

One example is this paper and the response to it by Dr. Krabbe. This paper can be understood as one turn of a dialogue, and Dr. Krabbe's response as the second turn of the dialogue.

Another example is a recent book by Gilbert Harman and Judith Jarvis Thomson, called Moral Relativism and Moral Objectivity (1996). In the first five chapters of this book, Harman defends a version of moral relativism. In the next three chapters, independently of Harman, Thomson defends a version of moral objectivity. In the ninth chapter, Harman responds critically to Thomsons's first three chapters, and in the tenth chapter, Thomson responds critically to Harman's first five chapters.

It would not be inaccurate to describe scholarly journal articles and scholarly monographs, in general, as like turns in dialogues. Assuredly, their authors are responding to doubts or questions raised against their positions and arguments by arguments against their positions, or against their premises, and by incompatible positions argued for elsewhere, to be found in the extant literature.

If all of these examples count as argument-dialogue turns, they are turns of level 13. complexity. Such dialogues, along with all of types grouped in C and D-while they presuppose the two sides Walton says are found with every argument-are "non-engaged" dialogues, like much of the Harman-Thomson exchange described above, or "quasi-engaged" dialogues, like the rest of that exchange. The interlocutors take up the same topic, defending (apparently) incompatible positions on it, but they do not interact directly with one another, stopping the flow of the arguments making up their case with questions or challenges. Even where they interact, each side chooses which of the views of the other side it wants to attempt to refute and which of its own claims it wants to support, and is not forced by questions or challenges from the other side to address the issues that other side deems important. The arguments in such dialogues, while addressed to another side, are solo performances, and I will call them "solo arguments." Non-engaged, or quasi-engaged, dialogues are to be contrasted to the types of dialogue grouped in A and B, which are of necessity engaged. The arguments of such engaged dialogues are like duets, and I will call them "duet arguments."

What is the significance of the difference between duet arguments and solo arguments, between engaged and non-engaged argument-dialogues? There seem to be several noteworthy differences in the properties of these two pairs.

\section{(1) Participation of the respondent}

One obvious difference is that with solo arguments the argument is not developed over a series of turns in which there are exchanges with the respondent. The respondent is typically physically absent, and in any case the argument must be developed without direct questioning from or interaction with the respondent. It is true that in 
many cases the identity of and the views held by the people on "the other side" are known. However, while that fact gives the proponent something to go on, there are often doubts about the precise interpretation of those views, and there are more likely to be doubts about how the respondent would reply to the premises or inference links used by the solo arguer.

The respondent's absence means the solo arguer has choices not available to the duet arguer. The solo arguer is free to take the argumentation in directions that are not envisaged by the questions of the respondent, and to refrain from taking up points that the other side might challenge him on.

Even when there is a dialogue of sorts, such as in the present case, when a paper followed by a response to it are presented together, the author of the paper is not exclusively in an interchange with the anticipated challenges of the respondent. Often the respondent's identity is unknown to the author, but even when it is known, the author cannot know in advance what all the respondent's challenges will be. The author might be able to predict some responses, but to the extent that the author wants to make new arguments, the respondent's reactions may in some cases be in principle unknowable in advance (as when the respondent's commitments relative to the new argument have not been stated or cannot be inferred). Moreover, the author's audience tends to be wider than the immediate respondent - just as this paper is presented to others besides Dr. Krabbe - and so the author must also anticipate generally known objections, known views that are incompatible with his position, and even possible reasonable objections that he himself can think of, all with that wider audience in mind.

\section{(2) Composition of the "respondent," or "other side"}

In many cases the precise identity and opinions of the respondents are not known. You cannot predict, for example, who will be reading your letter-to-the-editor. In many cases there is no single "other side," but a heterogeneous array of points of view, maintained from a wide range of theoretical backgrounds, by people whose information bases or belief stores vary enormously in kind, quantity and quality. An example of such a diverse audience is the electorate addressed by a politician in, say, a nationally-televised interview with a journalist. The commitment stores of the audience members or groups may conflict, and often do.

The solo arguer is free to choose which "audience" to address. He may try to address them all, or some particular group of them, or some idealized subset of them (or superset: think of Perelman and OlbrechtsTyteca's "universal audience" (1958)). These choices cannot always be based solely on the known cognitive attitudes of the audience, since by hypothesis in such cases these may be contradictory.

\section{(3) Norms}

In idealized engaged dialogue games, with their argument-generating duets, argument norms are standardly specified, and they are partly constitutive of the game in question. They can be enforced by the participants or by a judge. In real-life, "live," engaged dialogues, the participants are the guardians of argument norms, free to challenge the acceptability of problematic premises, the relevance of seemingly unrelated premises, and the sufficiency of the evidence supplied, according to their own favoured criteria of adequacy. The norms themselves can be challenged, leading to meta-arguments over procedural issues. However, whether such engaged dialogues be contrived games or live duets, the norms of argument that apply to them are fairly determinate.

On the other hand, in non-engaged dialogues in real life, the arguer has no such guidance as to the norms he is expected to satisfy. In some cases, his best recourse is to examine the current practice in the context and try to meet the norms exhibited therein. For example, different academic or scientific journals have their own norms, 
which are sometimes stated, and otherwise can be inferred from the papers they publish. But such norms are necessarily vague and flexible, and the judges who enforce them - the referees and editors of any one periodical, for example - are a variable group. In other cases, there is no guiding practice. Theorists can and do construct and commend sets of norms based on such factors as the aims of the interlocutors and the underlying purposes of the argument. The recommendation of such norms is part of Walton's project, I would say, if I understand it correctly. Perhaps some day such norms will have become unproblematic, well established, taught, and socially enforced, so that they then are part of the fabric of our argumentative lives. But under present circumstances the live solo arguer can make no such assumption. So the arguer has to make decisions, to try to meet the expectations of the audience (so far as he can guess at them), and to satisfy his own epistemic or decisionmaking standards.

Clearly, rules that might suit idealized engaged dialogue argumentation cannot apply to solo arguments in nonengaged dialogues. To see that this is so, consider some of the pragma-dialectical rules of van Eemeren and Grootendorst's rational disagreement-resolution argument dialogues_-what they call "critical discussions."

Some of the pragma-dialectical rules do not apply to solo arguments because the presuppositions of the rules are not satisfied. For example, the rule governing the handling of the other party's unexpressed premises (Rule 5 in 1992) $\underline{5}$ has no place when the solo arguer's audience is so diffuse that it cannot be held responsible for any particular argument in enough specificity to have identifiable unexpressed premises. Similarly, just what the audience accepts as starting-point premises can often not be known, so the pragma-dialectical rule governing such premises cannot be applied (Rule 6)․ The rule (No. 7) $\underline{7}$ that requires that the use of an appropriate argumentation scheme correctly applied is necessary for a standpoint to be regarded as conclusively defended may not be helpful to the letter-to-the-editor writer who wishes to argue for a proposition but must do so in 200400 words (or not be published), including also context-setting and any ancillary explanations or clarifications. The point is not that such arguments can be decisive while violating Rule 7; it is rather that the solo arguer in such a context can have no reasonable ambition of conclusively defending a standpoint in the space available, yet presumably not just anything goes. In such cases, then, because of the differences between solo arguments in non-engaged dialogues and duet arguments in engaged dialogues, these pragma-dialectical rules do not apply. Other norms are needed.

The variety of types of non-engaged dialogues suggests further that the search for a single set of norms is misguided. Consider a list of such dialogues:

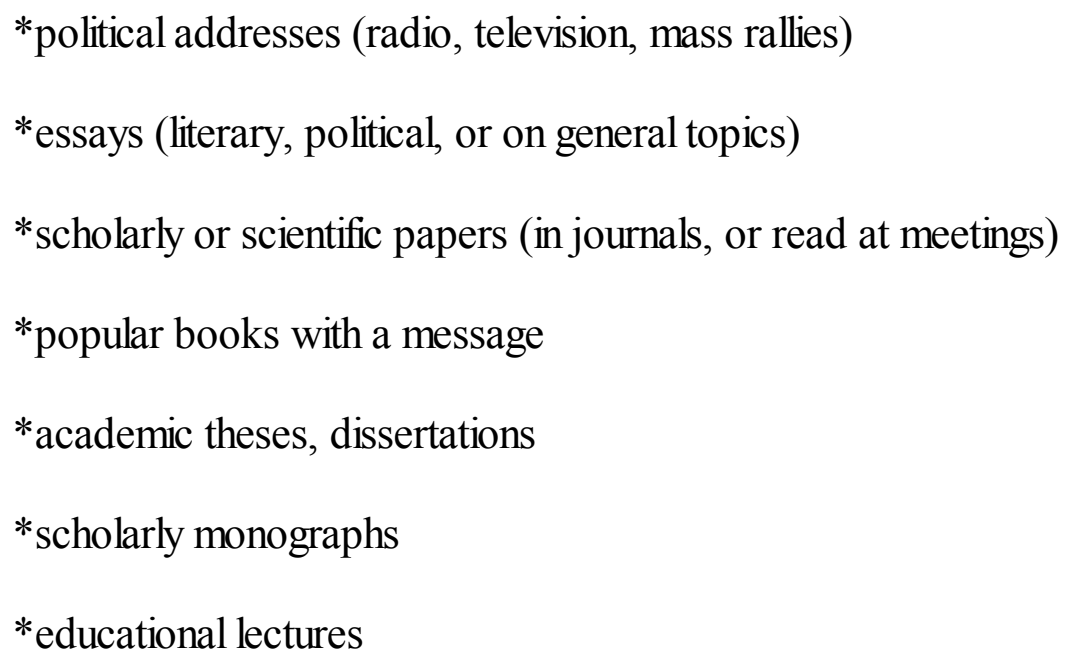

*motivational, inspirational speeches (coaches' locker-room speeches, business motivational 
talks, sermons in church or on TV, old-style convention speeches to the party faithful)

*individual educational lectures, courses of such lectures

On the face of it, what counts as a "good" argument in one of these contexts will not necessarily qualify as such in another. That is not merely because we can distinguish between different virtues of arguments, for example, rhetorical virtue and logical virtue. To be sure, a logically cogent argument can be ineffective in convincing its audience, and a persuasive argument can have gaping logical holes in it. However, the point I want to make about varying standards is a different one.

Let me use an example to make it. We as teachers and scholars are all familiar with the need to vary the nature of the arguments we use when in the lecture hall from those we use in the journal article. The qualifications, provisoes, distinctions, objections to be dealt with that are a must in our arguments when we go into scholarly print will only confuse, and lose the attention of, the students in the introductory class. Again, the confused views that we must labour to expose and refute in the introductory lecture do not (presumably) arise at all for the scholarly audience. Or yet again, it is counterproductive to use an argument, an analogy, say, whose emotional associations will side-track the students from the point to be made, but scholarly readers might be expected not to let their personal distaste for the subject matter of the analogy blind them to its implications.

Some might contend that the arguments for the introductory class are poor arguments and those for the scholarly article are good, or better, ones, but that would be a mistake. I am not at all suggesting that we use arguments we know to be fallacious when addressing introductory level students. The argument we use in the normal course

of events should be logically impeccable, or that should be our goal. What we cannot do at the introductory level, without defeating our purpose, is make as complete, or as fully qualified, a case as would be required to satisfy journal referees' appropriate expectations.

The variations I am suggesting lie along the dimensions of thoroughness or completeness, depth, selection, precision, qualification, and proviso. The standards for these criteria will vary with the context of the exchange. Their satisfaction requires an astute assessment of the cognitive and affective attitudes of the audience on the part of the solo arguer. None of these factors need worry the duet arguer, who has only to respond to the demands of his interlocutor.

\section{Conclusion}

I have spoken of "argument dialogues" as though the characterization as dialogues of such non-engaged complex exchanges as pairs of books were unproblematic. Robert Nozick's Anarchy, State and Utopia (1973) is in dialogue with John Rawls's A Theory of Justice (1971), and The Critique of Pure Reason is in dialogue with An Enquiry Concerning Human Understanding, on this account. But such talk is metaphorical, as surely as Whitehead was using a metaphor in characterizing Western philosophy as a series of footnotes to Plato. Dialogues proper, or strictly speaking, are exchanges among parties in which each takes a brief turn, and more or less responds to what was said in the immediately preceding and other previous turns. Thus only the members of Groups A and B, and perhaps some of group C, are dialogues. Plenty of arguments are delivered and considered outside the settings of such dialogues. 
While it stretches the concept of dialogue badly out of shape to try to fit into it all of the types of so-called "argument-dialogues" listed above, it is easy enough to understand the motivation to do so. There is something dialogue-like about Nozick's response to Rawls, and Kant's to Hume. More than that, we expect the solo arguer to behave as if he were in dialogue with his actual, or possible, or some ideal, audience, as well as with those in the solo arguer's community of discourse who have previously expressed themselves, especially those who have argued, in ways relevant to his thesis and arguments. It would be handy to have the terminology to distinguish the argument properties unique to duet arguments in dialogues proper (Groups A and B), from the argument properties that are common to both duet arguments and solo arguments.

Up to this point the word 'dialectic' has not figured in this paper. 1 Its omission was deliberate. A glance at the literature on argument and argumentation will show that the terms 'dialogue,' 'dialogical,' 'dialectic,' 'dialectics' and 'dialectical' are used either interchangeably, or with so much variation that they mark no unique distinction. 9 It will never happen, but it would be nice if the term 'dialectical' were reserved to denote the properties of all arguments related to their involving doubts or disagreements with at least two sides, and the term 'dialogue' were reserved to denote turn-taking verbal exchanges between pairs of interlocutors. Then I could use this terminology to express the points that (1) all argumentation is dialectical, but by no means is all argumentation dialogical, and (2) the dialectical properties of dialogues, and the norms derived from the dialogue model, do not all apply to non-dialogical argument exchanges, even though the latter are dialectical too. In other words both duet arguments and solo arguments are dialectical, but only duets are dialogues.

The suggestions of this paper have at least two implications worth noting. One is that studies of dialogues, such as Walton's, will not suffice to reveal all the salient properties of solo argumentation, nor all the norms appropriate to them. The other, which is undeveloped but lurks nonetheless, is that the rhetorical dimension of solo argument, the properties and norms entailed by the addressing of an audience by a rhetor, need to be explored more closely by the student of the pragmatic conception of argument.

\section{Notes}

1. Walton borrows most directly from van Eemeren and Grootendorst (1984), but the idea can be found in Barth (1982b), Krabbe (1982), Lorenz (1982), Lorenzen (1982), Naess (1966) and no doubt many others. See Walton 1989, 1992, 1996a, 1996b, Walton and Krabbe 1995.

\section{Republic I, 332c-333a.}

3. I borrow the term, by extension, from Caroline West's term, 'non-engaged dialogue,' which she uses (1997) to describe the Harman-Thomson exchange discussed below.

4. This concept of a "case" is discussed in Johnson and Blair (1993: 215-216) and (1994: 247-248).

5. "A party may not falsely present something as a premise that has been left unexpressed by the other party or deny a premise that he himself has left implicit." (1992: 208)

6. "A party may not present a premise as an accepted starting point nor deny a premise representing an accepted starting point." (1992: 209) 
7. "A party may not regard a standpoint as conclusively defended if the defense does not take place by means of an appropriate argumentation scheme that is correctly applied." (1992:209)

8. It appeared, in scare quotes, in a mention of Barth's use of it.

9. A good example is the ground-breaking proceedings of the 1978 Groningen Conference, Argumentation: Approaches to Theory Formation (eds. E.M. Barth and J.L. Martens, 1982), which was intended to focus on "the dialectical stage of the theory of argumentation" (viii), and had papers with titles including the following terms: "dialogische," "dialectical," "dialogues," "dialectics" and "dialogue logic." As far as I can tell, these terms are used in this collection without discrimination or distinction.

\section{References}

Barth, E.M. and Martens, J.L. (Eds.). 1982. Argumentation: Approaches to Theory Formation.

Barth, E.M. 1982a. Preface to Barth and Martens (1982): vii-xi.

Barth, E.M. 1982b. "A Normative-Pragmatic Foundation of the rules of Some Systems of Formal 3 Dialectics." In Barth and Martens (1982): 159-170.

Eemeren, Frans H. and Grootendorst, Rob. 1984. Speech Acts in Argumentative Discussions. Dordrecht: Foris.

Eemeren, Frans H. and Grootendorst, Rob. 1992. Argumentation, Communication and Fallacies, A Pragma-Dialectical Perspective. Hillsdale, NJ: Lawrence Erlbaum Associates.

Harman, Gilbert and Thomson, Judith Jarvis. 1996. Moral Relativism and Moral Objectivity. Oxford: Basil Blackwell.

Johnson, Ralph H. and Blair, J. Anthony. 1993. Logical Self-Defense. 3rd edition. Toronto: McGraw-Hill Ryerson.

Johnson, Ralph H. and Blair, J. Anthony. 1994. Logical Self-Defense. 1st United States edition. New York: McGraw-Hill.

Lorenz, Kuno. 1982. "The Criteria for the Choice of Rules of Dialectic Logic." In Barth and Martens (1982): $145-157$.

Lorenzen, P. 1982. "Die Dialogische Begründung von Logikkalkülen." In Barth and Martens (1982): 23-54.

Naess, Arne. 1966 Communication and Argument, Elements of Applied Semantics. Oslo: Universitetsforlaget.

Nozick, Robert. 1974. Anarchy, State, and Utopia. New York: Basic Books.

Perelman, Chaim and Olbrechst-Tyteca, Lucy. 1958. La Nouvelle Rhétorique: Traité de l'Argumentation. 
Paris: Presses Universitaires de France.

Rawls, John. 1971. A Theory of Justice. Harvard University Press.

Walton, Douglas. 1992. The Place of Emotion in Argument. Pennsylvania State University Press.

Walton, Douglas. 1989. Informal Logic, A Handbook for Critical Argumentation. Cambridge University Press.

Walton, Douglas. 1996a. Argumentation Schemes for Presumptive Reasoning. Mahwah, NJ: Lawrence Earlbaum Associates.

Walton, Douglas. 1996b. Argument Structure, A Pragmatic Theory. University of Toronto Press.

Walton, Douglas and Krabbe, Erik C.W. 1995. Commitment in Dialogue: Basic Concepts of Interpersonal Reasoning. Albany: State University of New York Press.

West, Caroline. 1997. Review of Gilbert Harman and Judith Jarvis Thomson, Moral Relativism and Moral Objectivity in Australasian Journal of Philosophy, 75, 1 (March): 116-117.

View Commentary by E.C.W. Krabbe

View Index of Papers and Commentaries

$\underline{\text { Return to Main Menu }}$ 